\title{
Crizotinib induced hypogonadism - a novel complication of lung cancer treatment
}

\author{
S.K. Lu' ${ }^{1}$, T. Thay ${ }^{2}$, S. Popat ${ }^{1}$ and D.L. Morganstein ${ }^{1,2}$ \\ 1 Royal Marsden Hospital, London \\ 2 Chelsea and Westminster Hospital, London
}

\section{Background}

Targeted treatments, such as tyrosine kinase inhibitors, are revolutionizing the treatment of cancer. However multiple endocrine side effects of these treatments are emerging, of which hypothyrodism appears to be the most common. Crizotinib, a multi-targeted small molecule tyrosine kinase inhibitor of ALK and c-met, has been approved by the FDA in 2011 for the treatment of NSCLC patients with a novel oncogenic gene fusion, EML4-ALK and its variants, following early phase trial showing an impressive response rate of $50-60 \%$ and median PFS of 10 months. Lowering of testosterone level has been described with crizotinib treatment and increases after interruption of treatment demonstrating a direct causal effect. Here, we report a case of hypogonadism with crizotinib treatment.

\section{History}

A 35 year old man, light ex-smoker, was diagnosed with stage IV adenocarcinoma of the lung in 2011. He progressed despite treatment with conventional chemotherapy. Gene rearrangement the ALK gene at $2 \mathrm{p} 23$ was detected by FISH testing. He therefore commenced crizotinib through compassionate supply in May 2012 and continues to be on it at present day and has attained an excellent partial remission. He tolerated the treatment reasonably well except the common known sideeffects including grade 1 rash, nausea, visual disturbance and diarrhoea. Random total testosterone level at baseline was within normal range and monitored at each clinic visit.

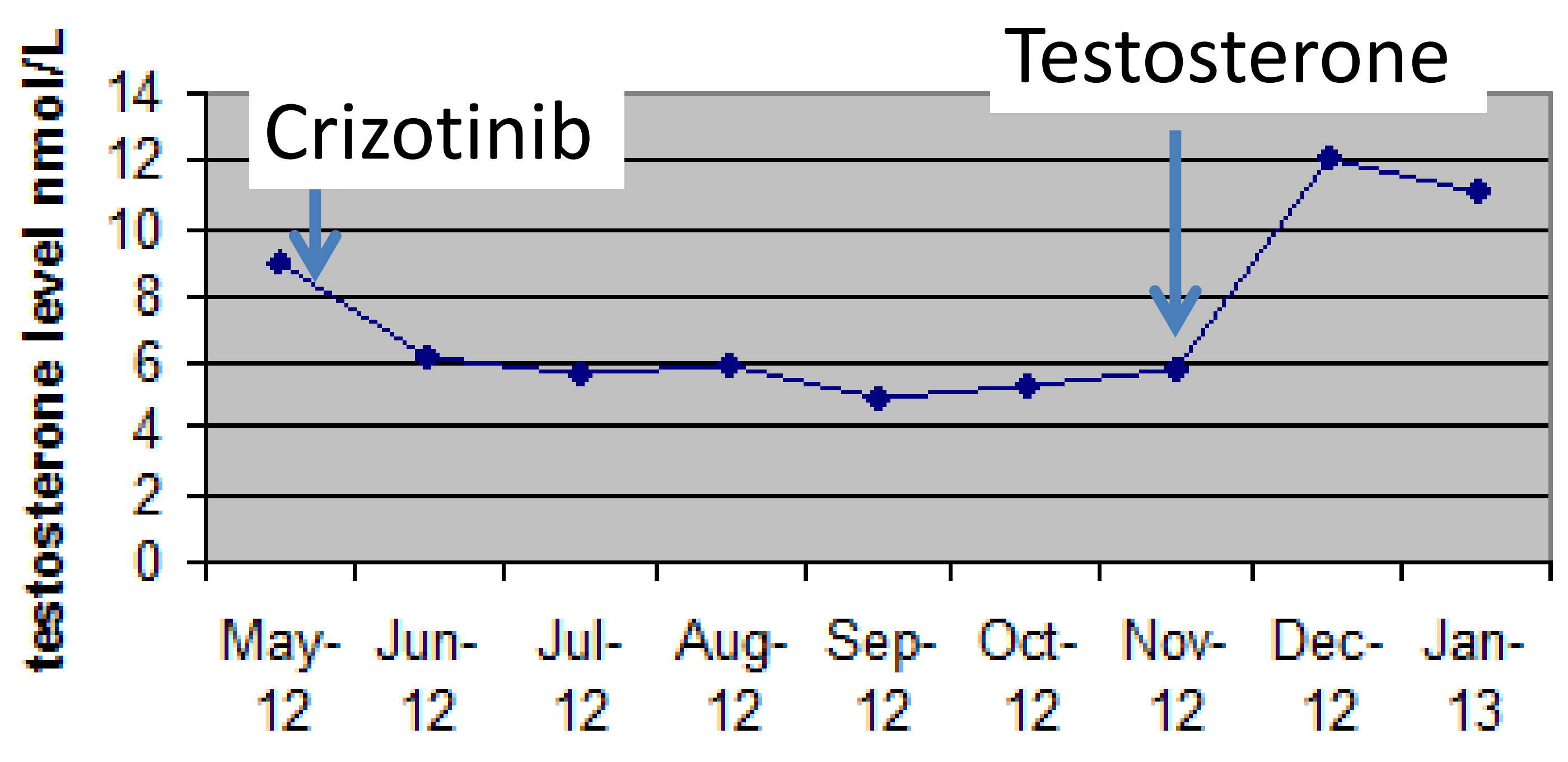

He developed symptoms of fatigue, loss of libido and absent morning erections.

Additional testing revealed an early morning testosterone level at 7.8, LH of 4.6 and an elevated FSH of 12.5. Interestingly, his SHBG was low at $8 \mathrm{nmol} / \mathrm{L}$ and prolactin was elevated, although he was taking metoclopramide. Despite the low SHBG, a calculated free testosterone was also low.
An MRI of his pituitary was performed to rule out a pituitary metastasis, which was reported as normal.

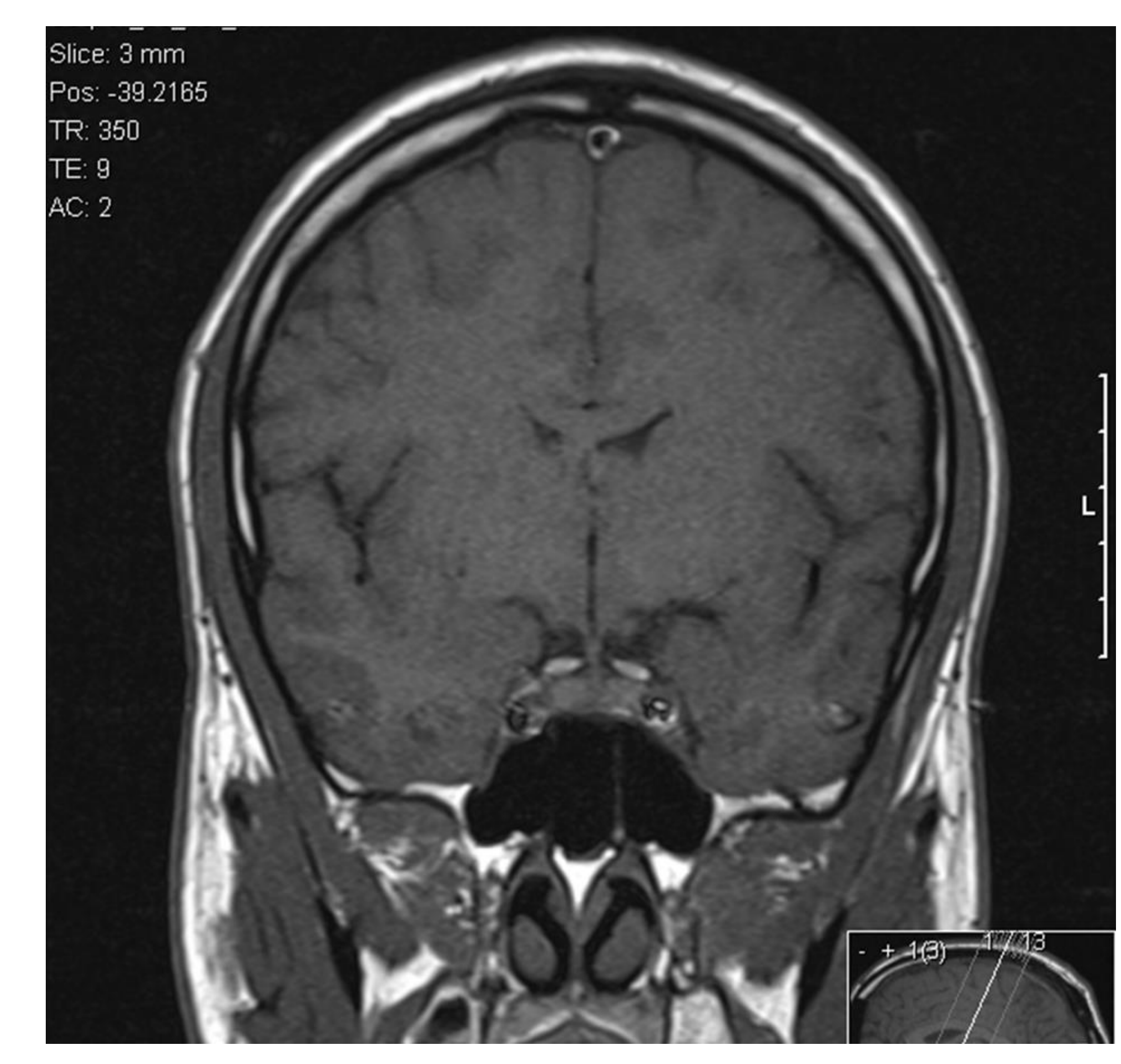

He was therefore commenced on testosterone replacement, with Testogel, with an increase of total testosterone into the lower end of the normal range, and suppression of his gonadotrophins, although his SHBG remained low. He had a good clinical response with increased energy levels and libido.

\section{Conclusions}

Crizotinib appears to frequently result in hypogonadism, by an unknown mechanism. The low SHBG seen in this case has not previously been described.

Treatment of the hypogonadism has resulted in improved symptoms.

Endocrinologists need to be aware of the potential endocrine side effects of new cancer treatments. 